\title{
EXPERIÊNCIA ESTÉTICA E ANTROPOCENO: POLITICAS DO COMUM PARA OS FINS DE MUNDO
}

AESTHETIC EXPERIENCE AND ANTHROPOCENE: POLITICS FROM THE COMMON TO THE ENDS OF WORLDS

\section{Marina Guzzo*}

Renzo Taddei**

*Artista e pesquisadora das artes do corpo, Marina Guzzo tem pós-doutorado pelo Departamento de Artes Cênicas da Escola de Comunicação e Artes da Universidade de São Paulo (ECA/USP) e mestrado e doutorado em Psicologia Social pela Pontifícia Universidade Católica (PUC-SP). Professora adjunta na Universidade Federal de São Paulo (Unifesp), no campus Baixada Santista; pesquisadora do Laboratório Corpo e Arte e coordenadora do Núcleo Indisciplinar de Dança [N(i)D/Unifesp]. Concentra suas criações na interface das linguagens artísticas e da incerteza da vida contemporânea, misturando dança, performance e circo para explorar os limites do corpo e da subjetividade nas cidades e na natureza.

**Professor de Antropologia na Universidade Federal de São Paulo (Unifesp), nos campi Baixada Santista e Guarulhos. Mestre e doutor em Antropologia pela Columbia University, em Nova York. Fez pós-doutorado na Universidade Estadual de Campinas (Unicamp). Coordenador do Laboratório de Pesquisas em Interações Sociotecnicoambientais (LISTA/Unifesp), pesquisador do Laboratório de Pesquisas Pós-Disciplinares da Universidade de São Paulo (LAPOD/USP) e do Center for Research on Environmental Decisions (CRED/ Columbia University). Trabalha com formas não ocidentais de compreensão e ação sobre a atmosfera. 


\section{RESUMO}

Este artigo pretende olhar para a produção artística que se posiciona na fronteira entre a performance, a dança e as artes visuais e o debate contemporâneo sobre o Antropoceno. Uma série de trabalhos e artigos nacionais e internacionais recorta diferentes maneiras de fazer arte nesse contexto e aponta questões para pensar e transformar os modos de existência frente a um futuro incerto, em um planeta em processo de destruição. Artistas, filósofos, cientistas, políticos, animais, plantas, rios e muitos outros existentes especulando, juntos, um futuro possível para os fins de mundos que se apresentam. Partimos do pressuposto que a(s) arte(s), a(s) ciência(s) e a(s) cultura(s) estão visceralmente relacionadas com as engrenagens ecogeopolíticas do real, e portanto apresentam-se como plataformas a partir das quais surgem novas possibilidades de pensar, diagnosticar, inventar e transformar o(s) tempo(s). Algumas perguntas são norteadoras de nossa reflexão neste texto: Como a arte e os fenômenos atrelados ao Antropoceno se relacionam? Como a prática artística pode endereçar mudanças políticas e sociais para o momento que nos encontramos, em termos planetários? Como a figura do artista pode propor novas narrativas, jogos e estéticas para uma humanidade em risco? E, em direção contrária, de quais formas o momento presente desarticula representações paradigmáticas sobre o fazer artístico e sua relação com os domínios da ciência e da política?

PALAVRAS-CHAVE: arte; antropoceno; performance; incerteza.

\section{ABSTRACT}

This article aims to look at artistic productions that place themselves at the frontier between performance, dance and visual arts, and the contemporary debate about the Antropocene. A series of works and articles, national and international, frame different forms of producing art in this context, and suggests questions that induce us to think and to transform modes of existence in face of an uncertain future, in a plant undergoing a process of destruction. Artists, philosophers, scientists, politicians, animals, plants, rivers and other beings speculating, together, a possible future for the ends of the worlds that are in place. We start from the presupposition that the arts, the sciences, and cultures are viscerally connected to the ecogeopolitical engines of reality, and therefore are platforms from which new possibilities of thinking, diagnosing, inventing and transforming the times spring. Some guiding questions for this text are: how are art and the phenomena linked to the Anthropocene connected? How can artistic practice address political and social change for the moment in which we find ourselves, in planetary terms? How can the figure of the artist propose new narratives, games and aesthetics for a humanity in risk? And, in reverse direction, in which ways the present times disarticulate paradigmatic representations about the artistic activity, and its relation to the domains of science and politics?

KEYWORDS: art; anthropocene; performance; uncertainty. 


\section{Antropoceno}

O fim do mundo voltou a ser elemento catalisador do pensamento de filósofos e cientistas no Ocidente (DANOWSKI; VIVEIROS DE CASTRO, 20I4). Se o apocalipse é tema clássico de mobilização do pensamento humano há milênios, há, no entanto, duas novidades no contexto presente. A primeira é que os mensageiros do fim do mundo vêm do grupo de pessoas menos afeito a metafísicas especulativas que a humanidade já produziu: físicos, químicos, climatólogos. ${ }^{1} \mathrm{~A}$ segunda é que a dimensão moral da hecatombe não é clara nem explícita - ainda que, como no passado, ela rapidamente tenha sido nomeada: trata-se de uma crise dos elementos, da Natureza (com "N" maiúsculo), da matéria. O termo Antropoceno foi criado pelo ecólogo Eugene Stoermer e popularizado pelo químico atmosférico e ganhador do Nobel, Paul Crutzen (2002). O conceito propõe designar a época (corrente) em que os efeitos da ação humana têm afastado o equilíbrio termodinâmico do planeta dos seus padrões históricos - daí o fato de que as mudanças climáticas (inicialmente denominadas "aquecimento global") sejam a manifestação mais visível dos seus efeitos. No entanto, o conjunto de transformações vai muito além da crise climática: em adição às mudanças da composição química da atmosfera em função de poluição e queima de combustíveis fósseis, estão as transformações do solo e dos ecossistemas, levando à redução dramática e acelerada da biodiversidade (configurando a sexta grande extinção de espécies de animais da história do planeta); a acidificação dos oceanos; o derretimento das geleiras, afetando a salinidade dos oceanos e as correntes marítimas; e a disseminação indiscriminada de plásticos, em forma de lixo, responsável pela contaminação de todas as cadeias tróficas - incluindo, portanto, a alimentação humana - com microplásticos. Em termos de ordem de grandeza, as estimativas sugerem que a ação humana move mais sedimentos no planeta do que todas as bacias hidrográficas somadas, e que a quantidade de energia que caracteriza as atividades humanas é comparável à da atividade das placas tectônicas. O ser humano passou a ser, verdadeiramente, uma força antibiogeológica na existência da geobiosfera. Uma intensa discussão científica recente diz respeito ao conceito de "limites planetários seguros" (planetary boundaries), que trata da questão da sustentabilidade ambiental global:

[...] tais limites planetários seguros foram avaliados para nove parâmetros relevantes: mudanças climáticas; perda de ozônio estratosférico; acidificação dos oceanos; ciclos biogeoquímicos de nitrogênio e fósforo; mudanças na integridade da biosfera associadas à perda de biodiversidade; mudanças no uso do solo; uso de recursos hídricos; carga de partículas de aerossóis na atmosfera; introdução de entidades novas e poluição química. (ARTAXO, 2014, p. 5).

\footnotetext{
${ }^{1}$ Ainda que, como Bruno Latour $(1994,2017)$ demonstrou em inúmeros livros, grande parte da objetividade das ciências ditas duras está construída sobre uma metafísica peculiar que divide o mundo em duas partes, "Natureza" e "Sociedade/Cultura", e que se faz invisível, em grande medida, aos próprios cientistas.
} 
Artaxo (2014) mostra que, ultrapassando esses limites, podemos (ou já estamos a) desestabilizar o clima excepcionalmente estável que tivemos ao longo de todo o Holoceno (período que se iniciou com o desgelo da última grande era glacial, há cerca de II.700 anos). Os limites seguros já foram ultrapassados em pelo menos quatro parâmetros (STEFFEN et al., 2015).

As mudanças climáticas e as mudanças na integridade da biosfera já são uma realidade para a maioria da população do globo. É notável que o fato de uma crise que é resultado da ação humana não evocar, como outrora, grandes rituais catárticos de redenção; em vez disso, clama-se por mais ciência, mais tecnologia, agora em escala planetária (na forma de geoengenharia - ver TADDEI, 20I7). No entanto, as imensas dificuldades envolvidas em construir conhecimento científico sobre o problema, traduzir tais conhecimento de maneira compreensível para a sociedade civil e o meio político, e induzir agentes econômicos e políticos a transformar seus padrões de atividade denotam que não se pode assumir que a humanidade tenha as ferramentas e as estratégias epistêmicas, cognitivas, emocionais e materiais para lidar com a questão. Nas palavras de Danowski e Viveiros de Castro (2014), sem as ferramentas conceituais e perceptivas necessárias é possível que o mundo acabe sem que sejamos capazes de perceber o fato (ou seja, vivendo-o de forma inarticulada, através do caos e do terror).

\section{Os lugares das artes no Antropoceno}

É justamente aí que as artes figuram de maneira proeminente nos debates sobre o Antropoceno, nos campos da filosofia e nas ciências sociais. A capacidade da atividade artística para construir novos regimes de percepção ganha força como recurso inestimável da existência humana para fazer frente aos desafios do momento presente. Ainda que não de modo inconteste, o Antropoceno evidencia a existência de aguda crise civilizacional, em que os construtos epistêmicos e filosóficos do passado (dos quais as tecnologias são materializações) mostram-se ineficazes. O pensamento contemporâneo sobre o Antropoceno identifica duas frentes fundamentais de trabalho: uma diz respeito ao papel criador de mundo das artes; outra, aos outros mundos, os mundos dos outros, através do contato com povos não ocidentais que se constituem e constituem seus mundos com outros construtos epistêmicos e outras estratégias ontológicas. Artistas e povos indígenas figuram, assim, no epicentro do debate filosófico contemporâneo.

O convívio entre artistas e cientistas é também espaço potente para a construção de novos sentidos sobre o Antropoceno. A preocupação com uma abertura à diversidade epistêmica tem sido um dos temas de referência em muitos trabalhos publicados recentemente em revistas científicas, livros e colóquios acadêmicos. Ao mesmo tempo, muitos artistas se baseiam em artigos e experimentos científicos para realizar práticas performáticas em torno do tema do Antropoceno. O próprio conceito de Antropoceno é, em si, uma ideia que circula e é colocada em disputa de maneiras diferentes, em diferentes campos.

Um dos pensadores centrais no debate sobre o papel da arte na composição do político é Jaques Rancière (2005), ao apresentar a arte como promessa de espaço comum. Isso acontece em 
função de a arte ser algo inútil, frágil e não produtivo, e pertencer a um tempo-espaço próprio; "e porque define uma experiência sensível desconectada das condições normais da experiência sensível e das hierarquias que a estruturam" (RANCIÈRE, 2005, s/p). Um elemento fundamental da reflexão desse autor consiste da caracterização da arte como manifestação coletiva, e não como categoria separada da vida. A não separação da arte e da vida é elemento potencializador para a elaboração conceitual e material do papel da arte no Antropoceno.

O efeito estético e político da obra de arte e de sua relação com a vida é o que Rancière (2005) denomina de "partilha do sensível". Essa concepção entende que um sistema de evidências sensíveis revela, ao mesmo tempo, a existência de um comum e dos recortes que nele definem lugares e partes respectivas. Isto é, compartilhamos um comum e temos nisso partes exclusivas: essas divisões partem-se ainda em divisões de tempos, espaços e tipos de atividades sensíveis, como na trama de um tecido. A partilha do sensível faz com que recortes de tempos e espaços, do visível e do invisível, da palavra e do ruído, definam ao mesmo tempo o lugar e o que está em jogo na política como tipo de experiência.

Rancière (2005) afirma ainda que é no campo estético que se trava uma batalha antes centrada nas promessas de emancipação da história. Com os embates e os dissensos do Antropoceno, a experiência estética acaba sendo um espaço privilegiado para tencionar posições nos embates políticos. A arte e a política dividem em comum posições e movimentos de corpos, funções das palavras; repartições do visível e do invisível. As práticas artísticas são maneiras de fazer que agem nas maneiras de ser e de visibilidade do ser/fazer.

Nesse sentido político, a arte tem a capacidade de criar novas formas cosmopolíticas (STENGERS, 2003) de contato entre existentes, por sua presença provisória, efêmera, mutante, como Rancière (2009) caracterizou o "regime estético" das artes. Esse regime opera para além das velhas questões do belo ou do sublime; nele a arte é responsável pela ativação de partições do sensível, bem como do dizível, do visível e do invisível, que, por seu turno, ativam novos modos coletivos de enunciação (LEPECKI, 2OI2) e de percepção, que, por sua vez e consequentemente, criam insuspeitados vetores de subjetivação e de novos modos de vida. Essas partilhas e distribuições do sensível surgem graças à força expressiva do objeto artístico, explicitando a relação de dissenso entre arte e política na contemporaneidade: "se existe uma conexão entre arte e política, ela deve ser colocada em termos de dissenso - o âmago do regime estético" (RANCIÈRE, 2OIO apud LEPECKI, 2OI2, p. 43).

A experiência estética deve, assim, construir as formas de uma vida comum em que arte e política, trabalho e lazer, vida pública e existência privada se confundam. Ela define, portanto, uma metapolítica, isto é, o projeto de realizar de fato aquilo que a política realiza apenas aparentemente: transformar as formas da vida concreta, enquanto a política se limita a mudar as leis e as formas estatais (RANCIÈRE, 2005). Dessa maneira, é a partir da experiência estética que surge a possibilidade da construção de configurações do real, onde possa existir, em um 
Antropoceno que não deixará de ser incerto e temido, utopias de construções coletivas e experimentação da igualdade e da liberdade.

Na confluência das ciências sociais e da filosofia, obras mais recentes dão um passo adiante no que diz respeito ao pensamento de Rancière, ao redefinir de maneira mais radical o campo político. Autores como Latour (20I4), Stengers (2015), Haraway (20I6) e Tsing (2015; TSING et al., 20I7) demonstram que, no contexto do Antropoceno (termo amplamente criticado e desconstruído pelos autores, particularmente Haraway e Tsing), a separação entre natureza e cultura não se sustenta, portanto a política não pode continuar reproduzindo o caráter antropocêntrico que há no pensamento ocidental desde pelo menos Aristóteles. Evidencia-se, desse modo, que as construções filosóficas e políticas de praticamente toda a história das civilizações ocidentais escoraram-se na estabilidade climática que caracterizou o Holoceno. Isso significa condições ecológicas estáveis o suficiente para que a percepção humana deixasse de perceber o protagonismo dos agentes não humanos nas questões mais salientes da existência das coletividades, criando a ideia de uma "Natureza" que existe como pano de fundo ou palco, inerte, sobre o qual a ação humana transcorre. Se tal estratégia política de despolitizar parte do mundo (a parte supostamente "natural") de fato nunca foi eficaz (LATOUR, 1994), é no Antropoceno, em que os distúrbios da ação humana desequilibram os ciclos termodinâmicos do planeta, que tal estratagema semiótico se faz perceptível. Para Latour (20I7), a natureza deixa, então, de ser o "lugar" onde a política ocorre e se transforma em outra coisa: não mais um tema necessário (a "ecologia") dentro dos embates políticos da contemporaneidade, mas as condições mesmas da possibilidade da existência de qualquer política (LATOUR, 2OI7). Isabelle Stengers (20I5) referese a tal transformação através da expressão "intrusão de Gaia", na qual processos atmosféricos, hidrológicos, geológicos e biológicos deixam de reproduzir padrões históricos (conhecidos ou não), passando assim a desorganizar os assuntos humanos em escalas inéditas. O mais dramático, diz Stengers (20I5), não é que o capitalismo não se importe com a atmosfera, mas que a atmosfera não se importe com o capitalismo.

Se os trabalhos de Latour (2017) e Stengers (2015) reconfiguram o campo da política, as contribuições de Tsing (2015) e Haraway (2016) "dissolvem", por assim dizer, o sujeito político clássico, o ser humano que pondera, negocia na Ágora, toma decisões racionais. Se a própria psicologia e as neurociências haviam denunciado há tempos que tal ser não passava de criação mitológica do racionalismo europeu (KAHNEMAN, 2003), o que fazem Tsing (2015) e Haraway (20I6) é desconstruir a própria coerência biológica do ser humano produzida por outra mitologia, a de um darwinismo que postula a distinção entre organismo e meio, e que, de certa maneira mimetizando o próprio pensamento liberal do contexto político onde surgiu, estabelece que a competição entre organismos produz o caminhar da evolução biológica. Nem autônomos nem produzidos por autopoiesis, os organismos são seres necessariamente compostos (Haraway [20I6], indo além, afirma que somos todos processos vivos de compostagem), seres híbridos e que necessitam das relações simbióticas com outros seres para manterem-se vivos. Estar vivo é ser 
parte de processos complexos de simbiogênese. O resultado dessa operação radical de desconstrução do sujeito da política não é a dissolução desta, como sempre temeram os detratores das neurociências, mas, ao contrário, a sua expansão para todos os contextos que produzem e são produzidos por relações de simbiose, o que equivale a dizer a todos os contextos onde existe vida.

É por essa razão que as autoras (HARAWAY, 20I6; TSING, 2015; TSING et al., 20I7) tecem duras críticas ao conceito de Antropoceno: o antropocentrismo sugerido pelo termo é enganador, inclusive pela maneira como pode desembocar em processos de reforço do próprio marco antropocêntrico (como no caso dos movimentos aceleracionistas ou pós-humanos). Trata-se, na opinião de Tsing (20I5), mais de um problema de projeção de escalas de ação do local para o global que resultam na aniquilação das relações simbióticas (e que ela identifica com a ideia de plantation, daí o conceito alternativo de plantationceno). Haraway (2016), em adição a isso, propõe a ideia de que o próprio esforço de colonização conceitual da crise planetária é sintoma do problema que o termo pretende nomear. Em razão disso, e em linha com sua proposta de que é preciso abandonar tentativas falocêntricas de circunscrição e adestramento do problema, e investir, ao invés disso, na construção de narrativas especulativas que possam transformar a existência dos seres, ela propôs o termo Chthuluceno. Sugere um momento em que os processos ligados à terra soterram as ambições desmedidas do racionalismo ocidental, e no qual os seres sobrevivem através da construção de relações de simbionarratogênese, ou seja, da constituição de mundos semióticomateriais que possibilitem a reconstrução das relações de coconstituição entre os seres.

A crítica à suposta homogeneização implicada no "antropos" evidencia que populações não ocidentais, como os povos indígenas, são afetadas pelo problema sem ter participado de sua gênese. Ao mesmo tempo, e em razão dessa mesma particularidade histórica de serem estrangeiros aos modos de vida e aos pensamentos ocidentais, que tais povos existem como evidências vivas dos limites das teleologias do progresso e da evolução, o que os torna agentes importantes no processo de pensar o mundo em chaves distintas. David Kopenawa e Bruce Albert, em A queda do ceú (2015), relatam justamente sua busca em alertar os napë (não indígenas) que a relação que eles têm com a natureza fará o céu cair; os xamãs são os agentes que "seguram o céu", com o auxílio dos xapiri, os espíritos da floresta.

\section{Arte e/no/do Antropoceno}

Precisamos de narrativas especulativas que transformem percepções e ações de modo a construir formas de existência que maximizem os processos de simbionarratogênese e simpoiesis. É importante pensar com que histórias contamos histórias, com que pensamentos pensamos pensamentos, com que ações acionamos ações, com que performance perfomamos performances, diz Haraway (2016), evocando o trabalho de Marilyn Strathern (1992). É nesse contexto que os trabalhos artísticos aqui apresentados nos colocam frente a questões como finitude, destruição, extinção, desaparecimento; e, ao mesmo tempo, oferecem espaços de afeto, esperança e beleza. 
Experiências estético-político-simpoiéticas, agenciadoras dos temas de urgência da vida contemporânea.

O exemplo inicial é a 32- Bienal de Arte de São Paulo, que aconteceu em 2016 e esteve repleta de trabalhos que contavam com a sobreposição de saberes sobre o mundo, transitando entre a arte, a ciência e a religião, com base no tema da incerteza. A exposição teve a curadoria de Jochen Volz e se propôs a traçar pensamentos cosmológicos, inteligência ambiental e coletiva, assim como ecologias naturais e sistémicas. Dentro dessa grande mostra que misturou pessoas, bichos e plantas, uma obra emblemática dessa sobreposição de saberes sobre o fim foi O peixe (20I6), de Jonathas Andrade (Figura I A e B). Situada em um território híbrido entre documentário (em diálogo com a tradição etnográfica do audiovisual) e ficção - o trabalho acompanhou pescadores que utilizam técnicas tradicionais de pesca, como rede e arpão, pelas marés e pelos manguezais de Alagoas, na espera pelo tempo necessário para capturar a presa. Cada pescador encenou uma espécie de ritual: retiveram os peixes entre os braços até o momento da morte, em uma espécie de abraço entre predador e presa, entre vida e morte, entre o trabalhador e o fruto do trabalho, no qual o olhar - do pescador, do peixe, da câmera e do espectador - desempenha papel crucial.

Figura 1 A e B. Fotogramas de 0 peixe (2016) - obra de Jonathas Andrade exibida na 32a Bienal de Arte de São Paulo.

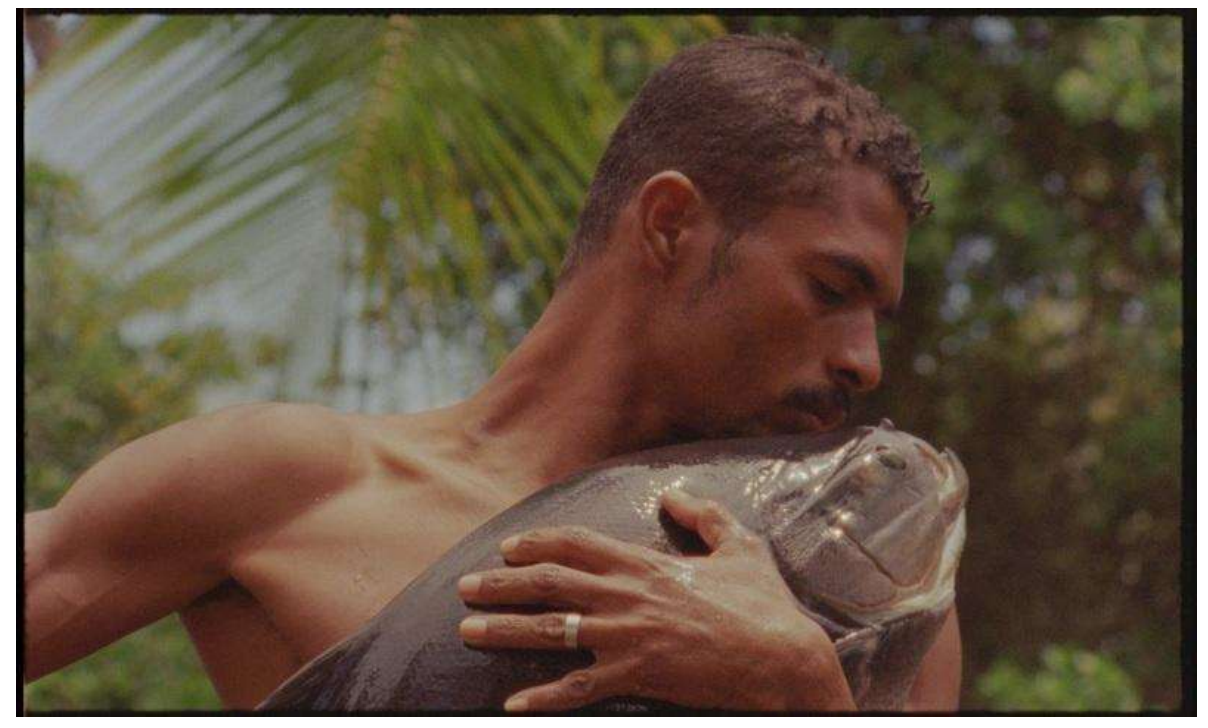




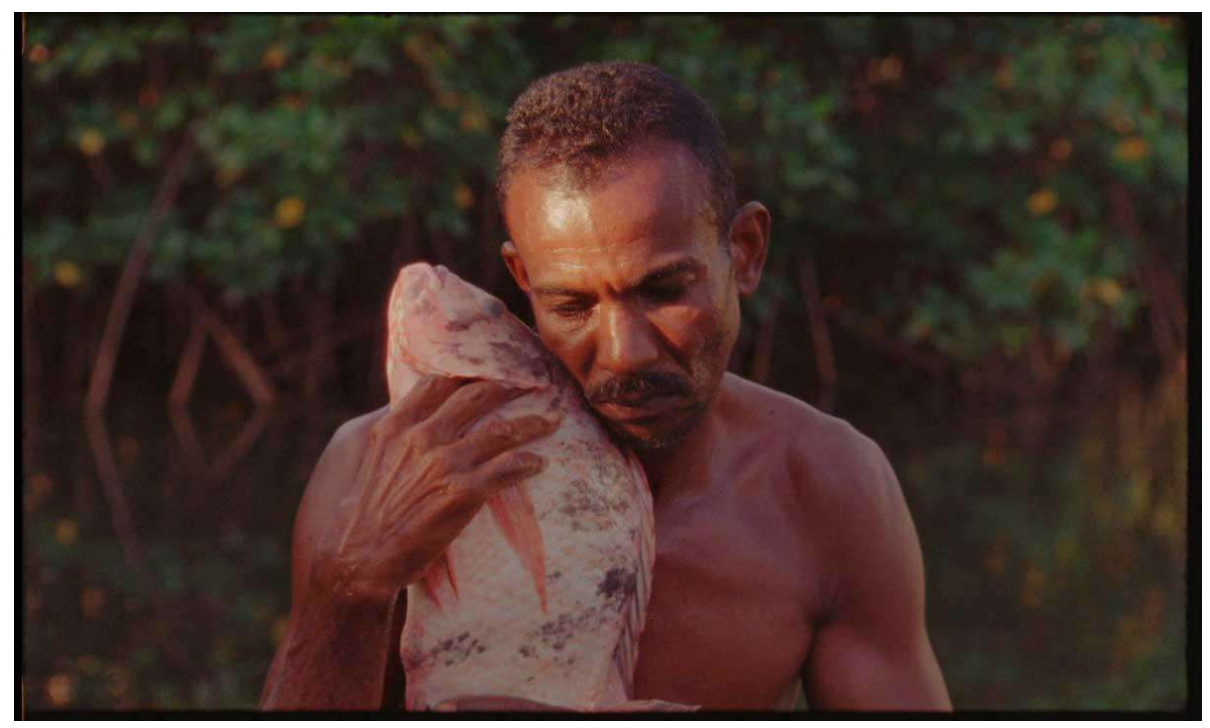

Fonte: <https://cargocollective.com/jonathasdeandrade/o-peixe>

A obra é angustiante, pois vivemos ali o momento perturbador da morte e como ele evidencia nossa falta de controle diante da vida. $O$ artista também escancara a relação do homem com a natureza, com sua ação de extermínio de espécies, seja para o próprio alimento, seja para a venda, para o ciclo econômico. Conseguimos enxergar a relação íntima do pescador com a pesca, e os sentimentos envolvidos na incerteza do que se passa no fim. Olhar para o fim da vida do peixe, mesmo no cotidiano do pescador, passa a ter outra dimensão: a de desestabilização de nossas frágeis narrativas sobre a vida e a morte.

Ao incluir narrativas de devires minoritários, a arte passa a ser um espaço de construção de outros mundos em sua relação com a natureza. A obra de David Kopenawa e Bruce Albert (2015), por exemplo, serviu de inspiração para a montagem do espetáculo Para que o céu não caia, da coreógrafa Lia Rodrigues, entre 2015 e 2016 (Figura 2 A e B). O trabalho foi descrito pela coreógrafa:

Diante de tantas catástrofes e barbáries que todos os dias nos assombram e emudecem, neste contexto de drásticas mudanças climáticas que escurecem o futuro, o que nos resta a fazer? Como imaginar formas de continuar e agir? O que cada um de nós pode fazer para, a seu modo, segurar o céu? Não há tempo a perder antes que tudo desabe. O céu já está caindo e aqui estamos nós a viver sob ele. Vamos juntar nossas forças mais íntimas para manter este céu. Cada um à sua maneira. Na Maré nós dançamos no ritmo de máquinas e carros, helicópteros, sirenes, nós dançamos sob um calor escaldante, nós dançamos com chuva e tempestade, nós dançamos como uma oferenda e como um tributo, para não desaparecer, para durar e para apodrecer, para mover o ar e para se expandir, para sonhar e para visitar lugares sombrios, para virar vagalume, para sermos fracos e para resistir. Nós dançamos para encontrar um jeito de sobreviver neste mundo virado de cabeça para baixo. Dançar para segurar o céu. É o que podemos fazer. (RODRIGUES, 20I6, s/p). 
Segundo Katz (2017), o trabalho de Lia Rodrigues fala do outro, justamente aquele que não conseguimos ouvir, "e nos mergulha no desconforto de precisar admitir não saber - a condição primeira para mudar algo" (KATZ, $2017 \mathrm{~s} / \mathrm{p}$ ). Trata-se da questão que parece colocar-se como central no Antropoceno: como mudar nossa sensibilidade e nossa relação com as pessoas, com o planeta e com si próprio em um contexto de desorganização de práticas, usos de artefatos, modos de deslocamento, alimentação, enfim, a maneira como nos organizamos social e culturalmente?

Figura 2 A e B. Para que o céu não caia, espetáculo de Lia Rodrigues.
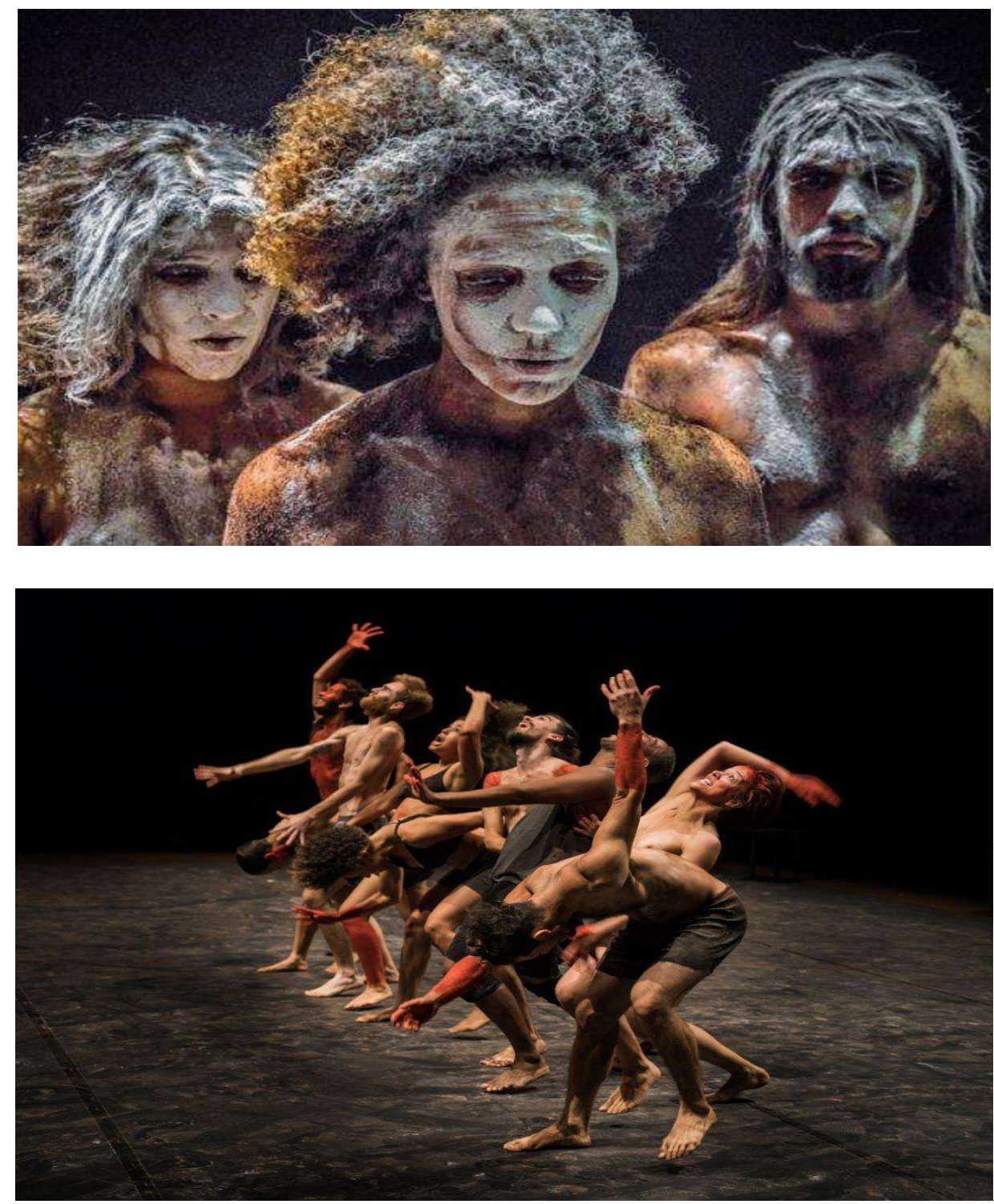

Fotos: Sammi Landweer

Nesse sentido, é Kopenawa (2015) que mais uma vez nos ajuda a entender os vários possíveis fins de mundos que teremos por meio da experiência dos Yanomamis, que tiveram de se reorganizar por muitas vezes a partir da invasão napë, e dos vários fins que vivenciaram depois dessa relação: a chegada de epidemias, o desmatamento, os fluxos de pessoas que mudaram a maneira como antes eles se relacionavam com a floresta. 
Interessa pensar os paralelos entre as enunciações de Kopenawa (2015) e de Lia Rodrigues (2016): de maneiras distintas, ambos constroem narrativas ricas em capacidade performativa, de fabulações agenciadoras de novas naturezas-culturas. Cada obra apresenta uma posição única que, partindo de relações criativas com a questão, involucram o leitor/público/espectador, de modo que o potencial de agenciamento opere em distintas escalas e níveis. Se essa dimensão constitutiva é mais ou menos explícita na performance artística, é mais sutil na obra de Kopenawa (2015). Eduardo Viveiros de Castro evidencia essa dimensão cosmogônica na obra do líder indígena, ao sugerir que ela é, dentre outras coisas, uma estratégia de tratamento xamânico dos seus leitores não indígenas (VIVEIROS DE CASTRO, 20I5).

É no contexto das interações/intervenções inspiradas na cosmovisão dos povos da floresta que outra obra emblemática se faz presente: a instalação The School of the Forest - Miami Campus, realizada pela artista plástica eslovena Marjetica Potrč, no Pérez Art Museum de Miami, em 2015 (Figura 3). A artista reproduziu dentro do museu uma construção típica das regiões do Acre em que ela testemunhou o encontro de detentores dos saberes indígenas e tradicionais com pesquisadores universitários, em condições de horizontalidade e aceitação da irredutível diversidade de existências, na iniciativa chamada Universidade da Floresta.

Figura 3. Marjetica Potrč: The School of the Forest - Miami Campus.

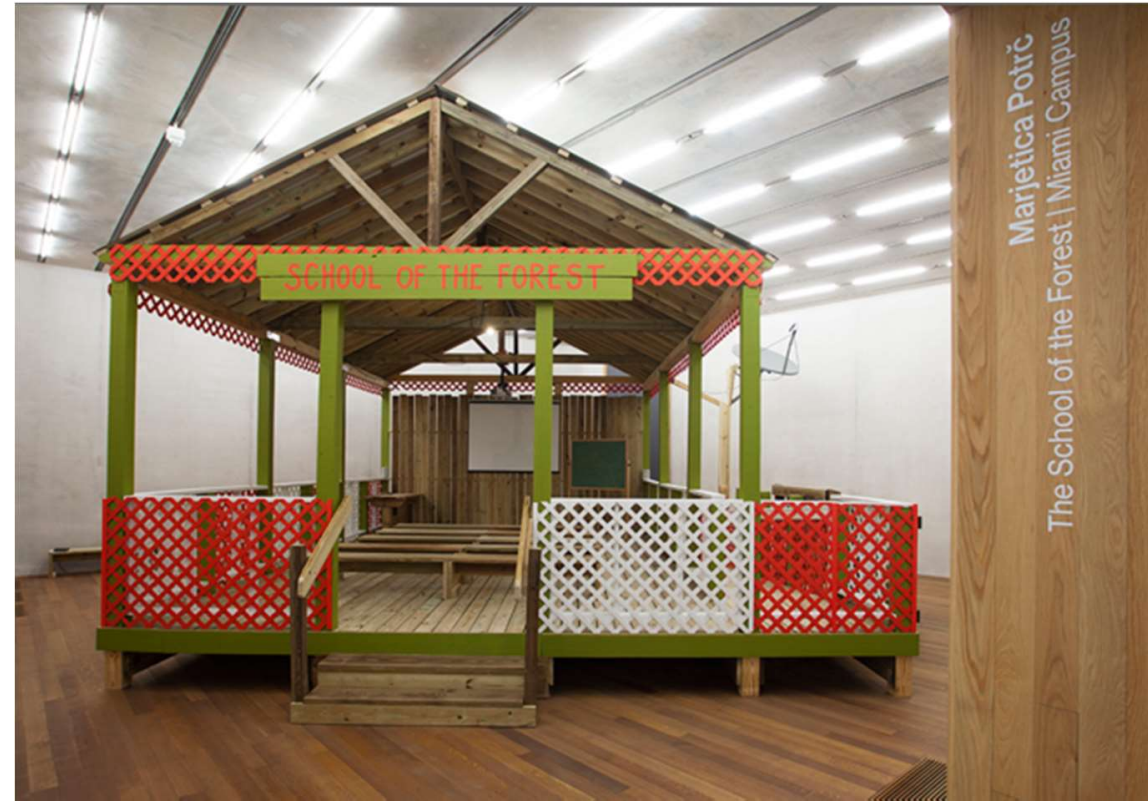

Foto: Oriol Tarridas . Fonte: <https://www.pamm.org/exhibitions/marjetica-potr\%C4\%8D-school-forest-miami-campus>

Outra obra de destaque é a de Harriet Hawkins et al. (2015), que analisam em um trabalho publicado nos Anais da Sociedade Americana de Geografia dois estudos de caso artísticos para problematizar o papel da arte nas transformações socioecológicas. Os autores trabalharam a partir de duas obras/ações: a primeira, "Bird Yarns", uma instalação de 90 pássaros de tricô, no Reino Unido, em resposta às mudanças nos padrões de migração das aves marinhas através das ilhas da Escócia (Figura 4 A e B). Trabalhando com lã local de Ardalanish e materiais reciclados, 
as bordadoras criaram um bando de andorinhas árticas "perdidas" no cais de Tobermory e forneceram às aves um evento com comida local, música e poesia. Kits de tricô foram desenvolvidos em parceria com produtores locais para destacar a situação das aves migratórias e celebrar os recursos da região. "Bird Yarns" é um coletivo das artistas Deirdre Nelson e An Tobar.

Figura 4 A e B. "Bird Yarns", instalação de Deirdre Nelson e An Tobar.

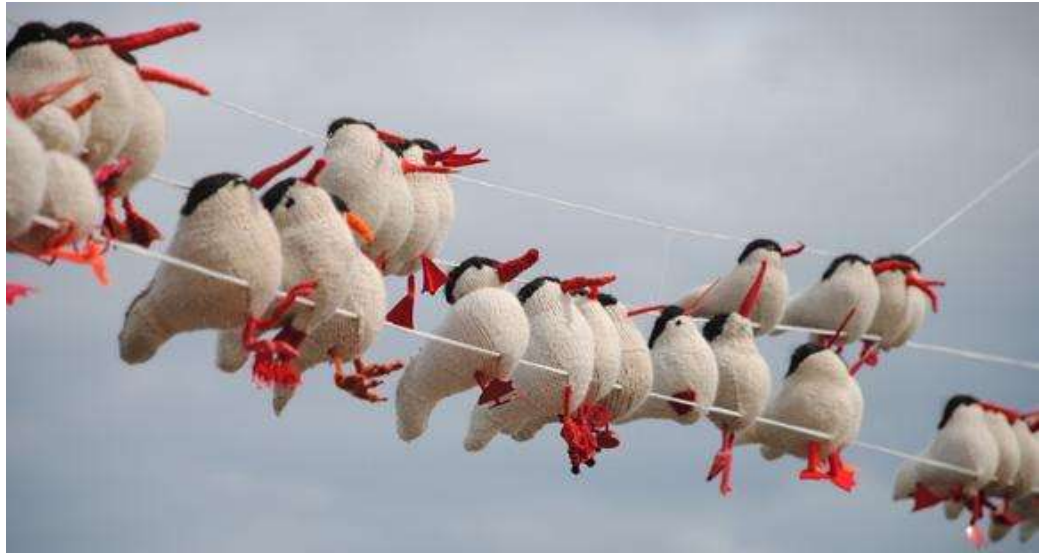

Fonte: <http://www.thelighthouse.co.uk/visit/exhibition/bird-yarns>

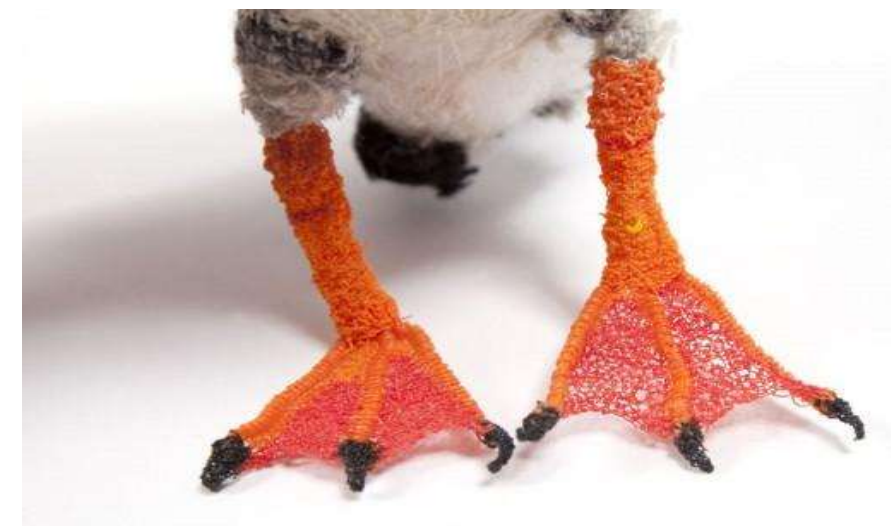

Fonte: <https://dovecotstudios.com/exhibitions/bird-yarns-20120926/>

O segundo trabalho analisado no artigo é a instalação/ação "SLOW Cleanup", um projeto de remediação ambiental dirigido pelas artistas Sallie Marston e Deborah Dixon. Com uma abordagem cultural para a recuperação ambiental de locais degradados, plantações são distribuídas pela cidade, de modo a auxiliar na recomposição dos ecossistemas contaminados, a partir das plantas. O projeto foi concebido para ser aplicado a postos de gasolina abandonados, legado da cultura automobilística. Essas formas de ruínas são predominantes em toda a paisagem urbana. Esses experimentos cívicos contribuem para a revitalização física e estética dos locais em que são instalados, ao mesmo tempo que criam oportunidades educacionais, reduzem as ilhas de calor e promovem o sequestro de carbono.

Hawkins et al. (2015) avaliam como algo recente esse interesse da geografia em "experimentações ativas e intervenções antecipatórias" em face dos desafios impostos pelas 
incertezas ambientais e sociais do Antropoceno. No artigo, a proposta é que existem duas dimensões sobre a força da arte em relação a essas preocupações: primeiro, ela apresenta um conjunto de práticas que cientistas, artistas e comunidades podem reconhecer e transformar nas relações entre humanos e não humanos. Em segundo lugar, encoraja a contabilização da força constitutiva da matéria e das coisas com implicações na política e na produção de conhecimento. Através dessas duas dimensões, os autores exploram como as artes podem possibilitar formas de transformação socioecológica e, além disso, como as coisas podem ser diferentes no futuro, permitindo-nos explorar quem, e o que, pode desempenhar um papel na definição e na direção de tal futuro.

No Brasil, a artista e pesquisadora Mari Fraga (2018), apresenta em sua pesquisa teóricoprática uma relação entre as artes visuais e os combustíveis fósseis (Figura 5 A, B e C). Discute como os efeitos da combustão aparecem como elemento principal do Antropoceno. Discorre sobre os estudos históricos da pirotecnologia - a aplicação do calor para transformar os materiais da Terra - e sugere que ao apresentar uma investigação abrangente sobre o uso do fogo humano, podemos trazer novas perspectivas para os desafios políticos e ambientais desse tempo em transformação. A autora sugere que a pirotecnologia, e sua atual contração e marginalização, influencia e modifica a estética política para o Antropoceno.

Outro trabalho de destaque é O teatro anatômico da terra, de Camila Sposati (2016) (Figura 6). A obra/instalação, que fez parte da $3^{\text {a }}$ Bienal de Arte da Bahia (2OI4), reproduziu na ilha de Itaparica um teatro anatômico nos moldes do que existiu em Pádua, na Itália, no século XVI, nos quais corpos eram dissecados. Em sua edição baiana, o teatro anatômico, incrustado na terra, construiu, através dos desafios de adentrar o solo - desafios estes que são físicos, geológicos, políticos, psicológicos e estéticos - novos regimes de visibilidade das relações multifacetadas da terra com humanos, com objetos, com o tempo e com a história.

A arte pode ser política a partir da crítica que estabelece em relação à realidade, questionando ou propondo possibilidades de ação e transformação das formas de existência. Nesse sentido, a arte tem o papel de testemunhar e coconstruir os sentidos da vida no presente. Ela é entendida, ao mesmo tempo, como um modo e um espaço de reflexão sobre as condições e as necessidades coletivas, mesmo quando não se propõe a isso de maneira específica. Por ser uma manifestação complexa (semiótica, material, biótica), ela agencia redes de materialidades e sociabilidades, e constrói maneiras singulares de narrar, posicionar-se, recortar e constituir a realidade. E como vimos em diversos exemplos citados nesse artigo, produzem narrativas potentes de construção e desconstrução do nosso imaginário no Antropoceno. 
Figura 5 A, B e C. Fotografias de 63 Perfurações e sua montagem na exposição Tempo Fóssil, realizada na Galeria Ibeu, Rio de Janeiro, em 2016. Performance orientada para vídeo, realizada pela autora. 25 min., 2015.

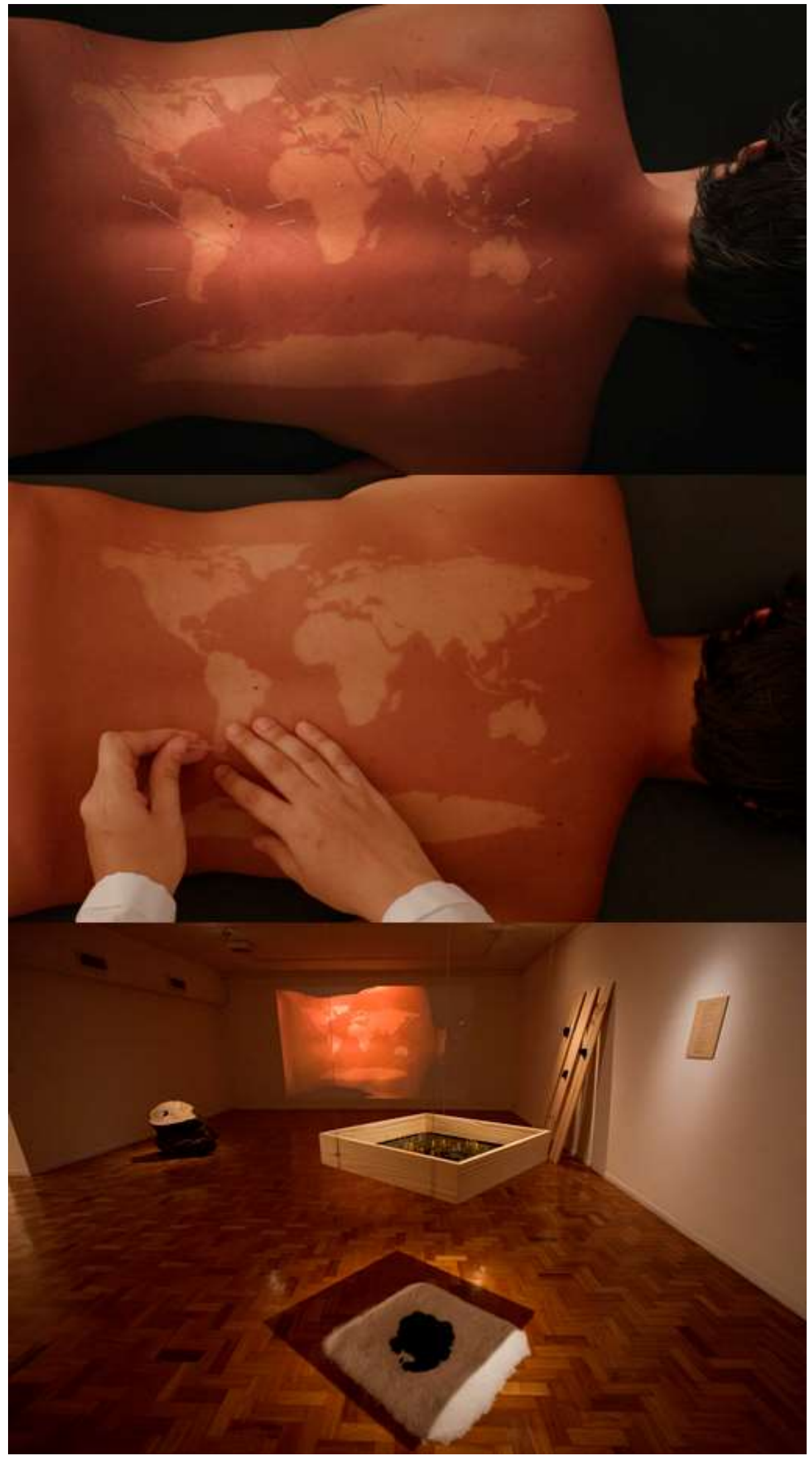


Figura 6. O teatro anatômico da terra.

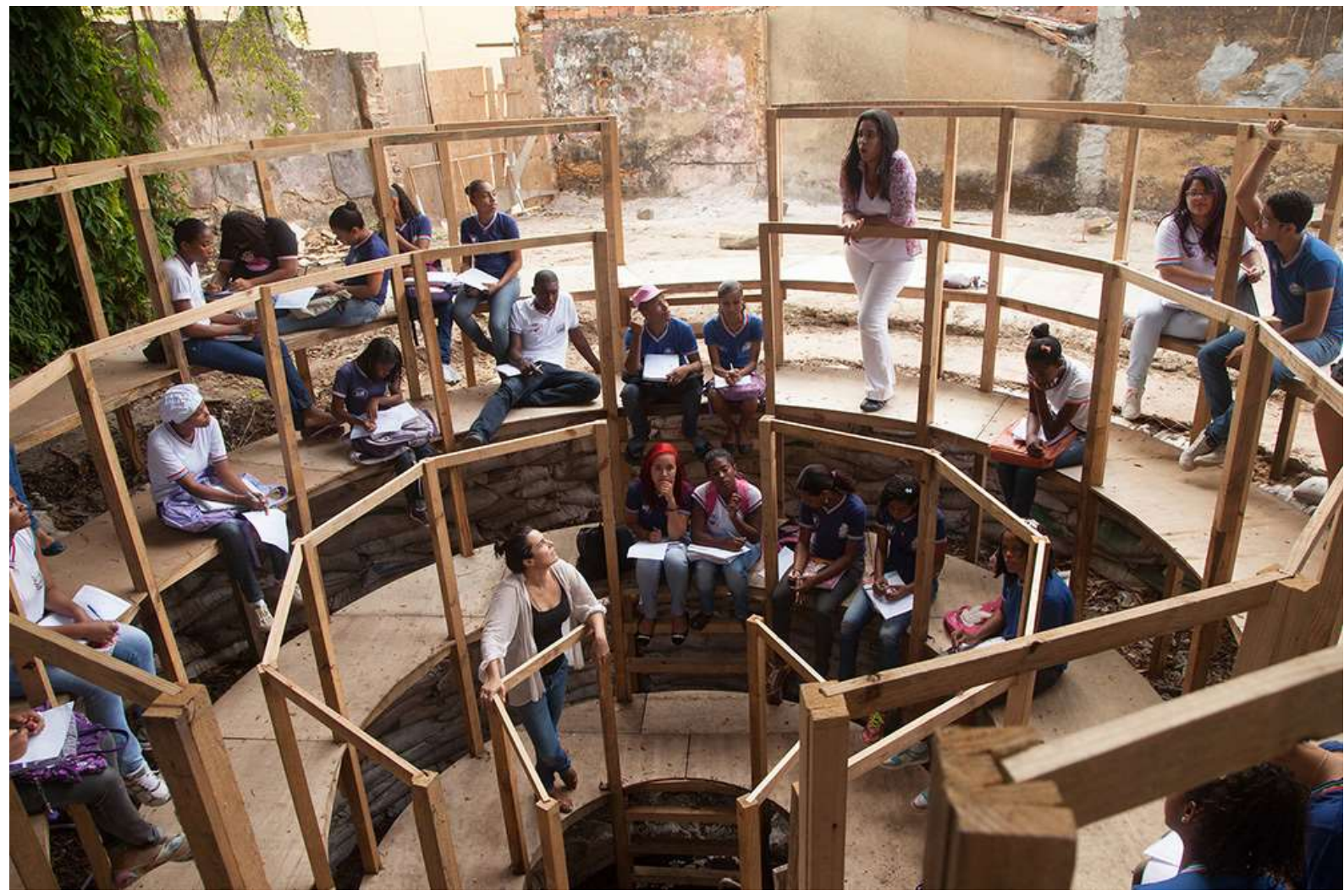

Fonte: $<$ http://camilasposati.com/teaching/>

\section{Referências}

ALONSO, C. Pràctiques artístiques, contextos discursius i humanitats mediambientals en l'època de l'antropocè. Artnodes: Revista D'art, Ciència i Tecnologia, n. 15, 2015. Disponível em:

$<$ https://www.raco.cat/index.php/Artnodes/article/view/303333>. Acesso em: 28 maio 2018. ARTAXO, P. Uma nova era geológica em nosso planeta: o Antropoceno?. Revista USP, n. IO3, p. I3-24, nov. 20I4. Disponível em:

$<$ https://www.revistas.usp.br/revusp/article/view/99279/97695>. Acesso em: 29 maio 2018.

CRUTZEN, P. Geology on mankind. Nature, v. 4I5, 2002.

DANOWSKI, D.; VIVEIROS DE CASTRO, E. Há mundo por vir? Ensaio sobre os medos e os fins. Florianópolis: Cultura e Barbárie Editora, 2014.

FRAGA, M. Tempo fóssil: petróleo, arte e corpo na cosmopolítica do Antropoceno. Rev. Bras.

Estud. Presença, Porto Alegre, v. 8, n. I, p. 3I-62, mar. 2018 . Disponível em:

$<$ http://www.scielo.br/scielo.php?script=sci_arttext\&pid=S2237-

$2660201800010003 \mathrm{I} \& \operatorname{lng}=\mathrm{en} \& \mathrm{nrm}=\mathrm{iso}>$. Acesso em: 28 maio 2018.

HARAWAY, D. Manifesto ciborgue. In: TADEU, T. Antropologia do ciborgue. Belo Horizonte: Autêntica, 2009.

HARAWAY, D. Staying with the trouble: making kin in the Cthulhucene. Durham; Londres: Duke University Press, 2016. 
HAWKINS, H.; MARSTON, S. A.; INGRAM, M.; STRAUGHAN, E. The art of socioecological transformation. Annals of the Association of American Geographers, v. IO5, n. 2, p. 33I-34I, 2015.

KAHNEMAN, D. Maps of bounded rationality: psychology for behavioral economics. American Economic Review, v. 93, n. 5, p. I449-I 475, 2003.

KATZ, H. 'Para que o céu não caia' guarda a fórmula da dança. O Estado de S. Paulo, São Paulo, 28 mar. 20I7. Disponível em: $<$ https://cultura.estadao.com.br/noticias/teatro-e-danca,para-queo-ceu-nao-caia-guarda-a-formula-da-danca,700oI7 I8039>. Acesso em: 27 out. 2019

KLEIN, N. Prepare-se para o capitalismo do desastre de Trump. Rio de Janeiro, The Intercept Brasil, 26 jan. 2017. Disponível em: <https://theintercept.com/2017/oI/26/prepare-se-para-ocapitalismo-do-desastre-de-trump/>. Acesso em: 27 out. 2019

KOPENAWA, D.; ALBERT, B. A queda do céu: palavras de um xamã yanomani. São Paulo: Companhia das Letras, 2015.

LATOUR, B. An inquiry into modes of existence - an anthropology of the moderns. Cambridge: Harvard University Press, 2013.

LATOUR, B. Facing Gaia: eight lectures on the new climatic regime. Hoboken: John Wiley \& Sons, 2017.

LATOUR, B. Jamais fomos modernos. Rio de Janeiro: Editora 34, 1994.

LATOUR, B. Para distinguir amigos e inimigos no tempo do Antropoceno. Revista de Antropologia, São Paulo, v. 57, n. I, p. II-3I, nov. 20I4. Disponível em:

<http://www.periodicos.usp.br/ra/article/view/87702 >. Acesso em: 23 jun. 2018.

LATOUR, B. Politics of nature: East and West perspectives. Ethics \& Global Politics, United Kingdom, v. 4, n. I, p. I-IO, $201 \mathrm{I}$.

LEPECKI, A. Coreopolítica e coreopolícia. ILHA, v. I3, n. I, p. 4I-60, jan./jun. 20II/2OI2.

RANCIÈRE, J. A partilha do sensível: estética e política. São Paulo: EXO/34, 2005.

RANCIÈRE, J. Aesthetics and its discontents. Cambridge/Malden: Polity Press, 2009.

RODRIGUES, L. Para que o céu não caia. ClimaCom Cultura Científica, ano o3, n. 06, "Territórios", 2016. Disponível em: $<$ http://climacom.mudancasclimaticas.net.br/? p=557 $>$. Acesso em: 27 jun. 2018.

SPOSATI, C. Stone Theatre. Berlim: Revolver Publishing, 2016.

STEFFEN, W.; RICHARDSON, K.; ROCKSTRÖM, J. et al. Planetary boundaries: guiding human development on a changing planet. Science, v. 347, n. 6223, p. 736, 2015.

STENGERS, I. Cosmopolitiques I e II. Paris: La Découvert, 2003.

STENGERS, I. In catastrophic times: resisting the coming barbarism. Londres: Open Humanities Press, 2015. 
STRATHERN, M. Cortando a rede. In: STRATHERN, M. O efeito etnográfico. São Paulo: Cosac Naify, 20I4.

STRATHERN, M. Reproducing the future: essays on anthropology, kinship and the new reproductive technologies. Manchester: Manchester University Press, 1992.

TADDEI, R. Alter geoengenharia. In: Meteorologistas e profetas da chuva: conhecimentos, práticas e políticas da atmosfera. São Paulo: Terceiro Nome, 2017. p. I89-205.

TSING, A. L. The mushroom at the end of the world: on the possibility of life in capitalist ruins. Princeton: Princeton University Press, 2015.

TSING, A. L.; BUBANDT, N.; GAN, E.; SWANSON, H. A.(Eds.). Arts ofliving on a damaged planet: Ghosts and monsters of the Anthropocene. Minneapolis: University of Minnesota Press, 2017.

TSING, A. L. et al. Anthropologists are talking - about the anthropocene. Ethnos, v. 8I, n. 3, p. 535-564, 2015a.

TSING, A. L. et al. Less than one but more than many: anthropocene as science fiction and scholarship-in-the-making. Environment and Society: Advances in Research, v. 6, n. I, p. I49-I66, 2oI5b.

VIVEIROS DE CASTRO, E. O recado da mata. In: KOPENAWA, D.; ALBERT, B. A queda do céu: palavras de um xamã Yanomami. São Paulo: Companhia das Letras, 20I5. p. II-4I. 